\title{
Plasticity of Scarpa's ganglion neurons as a possible basis for functional restoration within vestibular endorgans
}

\section{Cécile Travo ${ }^{1}$, Sophie Gaboyard-Niay ${ }^{1,2}$ and Christian Chabbert ${ }^{1,2 *}$}

1 INSERM U1051, Institute for Neurosciences, Montpellier, France

${ }^{2}$ Sensorion, Montpellier, France

\section{Edited by:}

Pierre-Paul Vidal, Universite Rene

Descartes, France

Reviewed by:

Hans Straka, Ludwig Maximilian University of Munich, Germany

Paul J. May, University of Mississippi

Medical Center, USA

${ }^{*}$ Correspondence:

Christian Chabbert, INSERM U1051,

Institute of Neurosciences in

Montpellier, Hopitâl St Eloi,

Montpellier 34090, France.

e-mail: christian.chabbert@inserm.fr
In a previous study, we observed spontaneous restoration of vestibular function in young adult rodents following excitotoxic injury of the neuronal connections within vestibular endorgans. The functional restoration was supported by a repair of synaptic contacts between hair cells and primary vestibular neurons. This process was observed in 2/3 of the animals studied and occurred within 5 days following the synaptic damage. To assess whether repair capacity is a fundamental trait of vestibular endorgans and to decipher the cellular mechanisms supporting such a repair process, we studied the neuronal regeneration and synaptogenesis in co-cultures of vestibular epithelia and Scarpa's ganglion from young and adult rodents. We demonstrate that, under specific culture conditions, primary vestibular neurons from young mice or rats exhibit robust ability to regenerate nervous processes. When co-cultured with vestibular epithelia, primary vestibular neurons were able to establish de novo contacts with hair cells. Under the present paradigm, these contacts displayed morphological features of immature synaptic contacts. Preliminary observations using co-cultures of adult rodents suggest that this reparative capacity remained in older mice although to a lesser extent. Identifying the basic mechanisms underlying the repair process may provide a basis for novel therapeutic strategies to restore mature and functional vestibular synaptic contacts following damage or loss.

Keywords: vestibule, primary neurons, sensory epithelia, synapse, plasticity, repair

\section{INTRODUCTION}

Impairment of synaptic contacts between cochlear hair cells and primary auditory neurons has been demonstrated to underlie hearing loss following acoustic trauma (Pujol and Puel, 1999; Ruel et al., 2007). Current debate focuses on whether or not the acute loss of afferent terminals is reversible or permanent (Kujawa and Liberman, 2009; Lin et al., 2011). In the vestibule, impairment of synaptic contacts between vestibular hair cells and their afferent nerve terminals arising from Scarpa's ganglion neurons may also cause several types of vestibular deficits. Although current methods of clinical evaluation preclude direct characterization of the state of synapses in the vestibule following inner ear impairment, indirect measurements of neural activity through video-nystagmography has previously demonstrated a correlation between alteration of nerve activity and vestibular deficits (Freyss et al., 1973; Haid and Mirsberger, 1985). Moreover, recent development of animal models of vestibular deficits confirmed an impact on primary vestibular synapses regardless of the origin of the impairments. Swelling of the post-synaptic terminals, often followed by synapse uncoupling, were reported upon ototoxic (Seoane et al., 2001; Vignaux et al., 2012) or excitotoxic (Liu, 1999; Shimogori and Yamashita, 2004; Brugeaud et al., 2007) vestibular insult in adult mammals. Excitotoxic damage results from the overactivation of glutamate receptors by excessive release of neurotransmitter (Olney, 1969). This leads to a massive entry of calcium and sodium into the neurons that induce both swelling of nerve terminals and subsequent activation of apoptosis. Such pathological conditions are believed to occur following local ischemia and temporal bone trauma. As in the cochlea, questions remain on the transitory or permanent nature of the synaptic impairments. Recent clinical observations revealed that recovery of vestibular activity occurs within days or weeks following an acute impairment: partial recovery of the vestibular activity determined by VOR measurement was reported in 35\% of patients with vestibular neuritis (Choi et al., 2007). It is therefore of interest to define whether this functional recovery effectively relies on endogenous repair of peripheral sensory synapses. Central compensation is assumed to also support part of the functional recovery.

Spontaneous regeneration of vestibular receptors and their innervating afferents is well documented in birds, reptiles and, amphibians (Hernandez et al., 1998; Zakir and Dickman, 2006; Haque et al., 2009), but it has long been thought that this repair capacity was restricted to non-mammals. However, we recently reported the first evidence of spontaneous vestibular synaptic repair in adult mammal following mild excitotoxic damage (Brugeaud et al., 2007). Although local delivery of kainic acid in the middle ear of young adult rats evoked acute swelling of nerve terminals at synapses with hair cells, endogenous repair occurred in the days following the lesion. This synaptic repair was proposed to support, at least in part, spontaneous restoration of the vestibular function taking place during the same time frame. 
The present study was designed to further investigate and extend understanding of the capacity of primary vestibular neurons for re-afferentation of hair cells following synaptic damage and loss. Here we achieved complete vestibular de-afferentation by isolating both vestibular epithelia and Scarpa's ganglions from rodents and studied the ability of primary vestibular neurons to grow de novo neurites and re-innervate hair cells under co-culture conditions. Most experiments were performed using neonate rodents to take advantage of the highly plastic young tissue and to investigate the effect of different factors such as Brain Derived Neurotrophic Factor (BDNF) and Protein Kinase C (PKC) on such re-innervation potential. We also report preliminary experiments with adult tissue that extend these plastic capacities to mature rodents and bring new perspective on repair within vestibular sensory organs of adult mammals.

\section{MATERIALS AND METHODS ANIMALS}

Experiments were performed using newborn, postnatal day 29 (P2-9) and young adult (1 month old), and adult (3 month old) wild type rodents (Wistar rats and Swiss mice, CERJ, Le Genest, France) in accordance with the French Ministry of Agriculture regulations and European Community Council Directive no. 86/609/EEC, OJL 358. All efforts were made to minimize the number of animals used and their suffering.

\section{REAGENTS}

Phenol-red free Matrigel matrix was purchase from Becton Dickinson (Pont de Claix, France). Leibovitz medium, N2 supplement, Dulbecco's Modified Eagle medium with Ham's F12 nutrient (DMEM/F12), and $15 \mathrm{mM}$ Hepes were purchased from Invitrogen (Cergy Pontoise, France). BDNF was a Peprotech product purchased from TEBU-bio (Le Perray en Yvelynes, France). Phorbol 12-myristate 13-acetate (PMA), laminin, fish gelatin, and protease inhibitor cocktail were purchased from Sigma-Aldrich (Saint Quentin Fallavier, France). Normal swine serum was purchase from Jackson Immuno Research Europe (Cambridge, UK).

\section{D ORGANOTYPIC CO-CULTURES}

The protocol for co-cultures of vestibular sensory epithelia and primary ganglia was derived from the $3 \mathrm{D}$ cell culture protocol previously detailed (Gaboyard et al., 2005). Briefly, vestibular epithelia and ganglia were aseptically removed from animals and carefully dissected in Leibovitz medium. Explants were put in a drop of phenol-red free Matrigel $(15 \mu \mathrm{L})$ placed on laminin $(10 \mu \mathrm{g} / \mathrm{mL})$ coated glass coverslips with utricle, crista, and ganglion carefully oriented and positioned close to each other before jelling of the extracellular matrix. These preparations were incubated for $30 \mathrm{~min}$ at $37^{\circ} \mathrm{C}$ in a $95 \% / 5 \% \mathrm{O}_{2} / \mathrm{CO}_{2}$ atmosphere, at saturating moisture. Then, co-cultures were fed with culture medium DMEM/F12 $15 \mathrm{mM}$ Hepes supplemented with N2 cocktail (2\%). Treatments in some cases with BDNF $(10 \mathrm{ng} / \mathrm{mL})$ or PMA $(0.1 \mu \mathrm{M})$ were performed during the entire culturing period: the drugs were added to the culture feeding medium from seeding to fixation. The feeding medium was renewed every 3 days. BDNF experiments were performed using explants from both mice and rats while PMA experiments only used rat tissue. For each age and condition, cultures from 3 to $12 \mathrm{~L}$ were initiated and fixed over time to follow the time course of re-innervation and explore newly formed synaptic contacts. Figures are illustrative of several independent and repeated experiments, of which the total number is indicated in the Section "Results."

\section{ANTIBODIES}

Different combinations of primary antibodies were used. In most cases, a mouse monoclonal anti-neurofilament $200 \mathrm{kDa}(1: 500$; clone N52, Sigma-Aldrich) and rabbit serum anti-calretinin (1:3500; Swant, Marly, Switzerland) or for few experiments, rabbit serum anti-S100 $\beta$ (1:200; Swant) were used. In the remaining experiments, mouse monoclonal anti-CtBP2 to label the protein ribeye, a molecular constituent of ribbon dense core (1:350; BD Transduction Laboratories, Franklin Lakes, NJ, USA), rabbit serum anti-synaptophysin (1:500; Dako, Glostrup, Denmark) and goat serum anti-calretinin (1:3500; Swant) were mixed. Fluorescent secondary antibodies were donkey sera conjugated to Alexa-488 anti-mouse, Alexa-594 anti-rabbit, and Alexa-647 anti-goat IgG, respectively (1:700; Fisher Scientific).

\section{IMMUNOCYTOCHEMISTRY}

Co-cultures were fixed in $4 \%$ paraformaldehyde (PFA) for $2 \mathrm{~h}$, followed by methanol for $30 \mathrm{~min}$ at $-20^{\circ} \mathrm{C}$. Non-specific sites were blocked and permeabilization was performed by immersing the samples overnight at $4^{\circ} \mathrm{C}$ in a Tris/ $\mathrm{NaCl}$ solution (Tris $100 \mathrm{mM}$ with $\mathrm{NaCl} 1.5 \%, \mathrm{pH}: 7.4)$ containing $10 \%$ swine serum, $0.5 \%$ fish gelatin, $0.2 \%$ Tween-20, $0.1 \%$ Triton X-100, and $0.1 \%$ protease inhibitors. Samples were then incubated with primary antibodies for $48 \mathrm{~h}$ at $4^{\circ} \mathrm{C}$ diluted in Tris/ $\mathrm{NaCl}$ solution with $5 \%$ swine serum, $0.1 \%$ fish gelatin, $0.02 \%$ Tween- $20,0.01 \%$ Triton $\mathrm{X}-100$, and $0.1 \%$ protease inhibitors. Specific labeling was revealed with fluorescent secondary antibodies $(1: 1000)$ in Tris/ $\mathrm{NaCl}$ solution eventually combined with ToPro (1:1000) staining overnight at $4^{\circ} \mathrm{C}$. Samples were observed with a Zeiss 5 live duo laser scanning confocal microscope (MRI INM, Montpellier). Final image processing was done with Adobe Photoshop software (San Jose, CA, USA).

\section{TRANSMISSION ELECTRON MICROSCOPY}

Co-cultures ( $n=2 ; 18$ DIV from P6 rats) were fixed with $1.2 \%$ PFA and $0.25 \%$ glutaraldehyde directly added into the medium for $48 \mathrm{~h}$ at $4^{\circ} \mathrm{C}$. A post-fixation in PBS with $1 \%$ PFA, $2.5 \%$ glutaraldehyde, $1 \%$ picric acid, and $0.1 \%$ glucose followed for $3 \mathrm{~h}$ at room temperature. Then, samples were postfixed in $0.5 \% \mathrm{OsO}_{4}$, dehydrated, and embedded in EmBed 812-DER 736 (Delta Microscopies, Aigues Vive, France). Silver-gold ultrathin sections (80-90 nm) were collected, stained with uranyl acetate (RHEM INM, Montpellier, France) then viewed and digitized in a Hitachi H7100 electron microscope (CRIC, Montpellier, France).

\section{RESULTS}

\section{PRIMARY VESTIBULAR NEURONS PREFERENTIALLY ORIENT NEURITE} OUTGROWTH TOWARD SENSORY EPITHELIA

Once removed from the inner ear of neonate mice or rats, isolated vestibular endorgans were cultured as $3 \mathrm{D}$ organotypic explants as previously reported (Gaboyard et al., 2005). Under these conditions hair cells rapidly recovered from the isolation procedure while an endolymphatic compartment containing enriched $\mathrm{K}^{+}$ 
liquid regenerated (Bartolami et al., 2011). In the present study, vestibular (Scarpa's) ganglia were also dissected and co-cultured in the vicinity (within a distance of $0.5-1 \mathrm{~mm}$ ) of the sensory epithelia (utricles and cristae ampullaris). During the first 3 days in vitro (DIV), both the proximal (not shown) and distal (Figure 2A) nerve processes of primary vestibular neurons degenerated after being severed from their targets or cell bodies respectively. Subsequently, de novo neurite outgrowth was observed. Bundles of fibers arising from Scarpa's ganglion neurons with preferential orientation toward the sensory epithelia were clearly observable in all co-cultures after 6 DIV (mice $n=12$; rats $n=10$; Figures 1A,B). As BDNF was previously demonstrated to play a critical role during developmental innervation of sensory epithelia by vestibular primary neurons (Ernfors et al., 1995), we used the co-culture model from young rodents to examine the effect of BDNF addition on de novo neurite outgrowth. When BDNF $(10 \mathrm{ng} / \mathrm{mL}$; mice $n=4$; rats $n=4$ ) was added to the culture medium, the orientation of de novo neurite outgrowth was significantly altered (Figure 1C), forming a radiating pattern from Scarpa's ganglia, and only occasionally still innervating the sensory epithelia. This observation confirms the role of BDNF in the guidance of neuritis during the innervation of sensory epithelia. It agrees with studies that show controlled release of BDNF by the targeted cells or their immediate environment is required for innervation of sensory epithelia by primary vestibular neurons (Brugeaud et al., 2007). Schwann cells have also been shown to play an important role in the guidance of neuronal processes toward their targets during peripheral nerve regeneration (Zhang and Yannas, 2005). Using immunostaining of the $S 100 \beta$ protein, specifically expressed in vestibular glial cells (Bartolami et al., 2003), we confirmed that Schwann cells were part of the re-innervation process in the co-culture preparation. Indeed, the neuritic outgrowth of nerve fibers was never observed without accompanying Schwann cells (rats, $n=4$; Figure 1D).

\section{PRIMARY VESTIBULAR NEURONS FORM CELL-TO-CELL CONTACTS WITH HAIR CELLS WHEN CO-CULTURED WITH SENSORY EPITHELIA}

At $3 \mathrm{DIV}$, no remaining severed nerve processes were observed in sensory epithelia $(n=8$; Figure $2 \mathrm{~A})$. Conversely beginning at $6 \mathrm{DIV}$, growing neuronal processes arising from vestibular primary neurons entered the sensory epithelia in all co-cultures (mice and rats; $n=20$ ). High magnification observations indicated that the neuronal processes formed cell-to-cell contacts with the hair cells (Figures 2B,C). In most cases, growing neuronal processes established contacts with multiple hair cells. Surprisingly, at this time
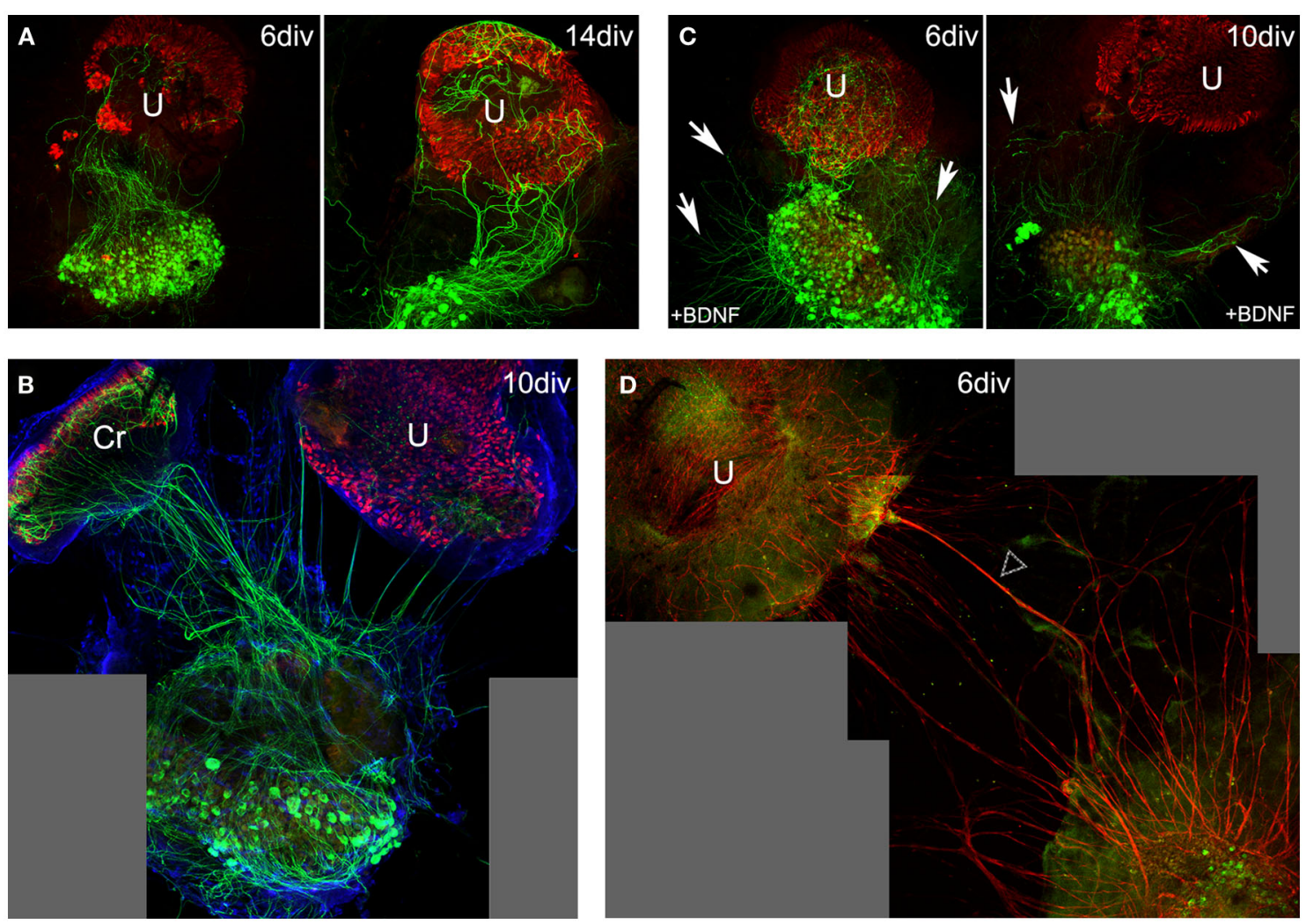

FIGURE 1 | Neurite outgrowth in 6-14 DIV co-cultures from P3-8 rodents. In co-cultures of vestibular ganglion, crista $(\mathrm{Cr})$, and utricle (U) from P5 mouse (A) or rat (B) pups, neurons extend processes toward the sensory epithelia. Neurofilaments (green) were stained with anti-N52 antibodies, hair cells (red) with anti-calretinin serum, and nuclei (blue) with ToPro3. The importance of extrinsic factors was highlighted in these culture conditions (C,D). BDNF added to the culture medium [P5 mice;
(C)] enhances neurite outgrowth, but its presence in the culture medium disrupts with the natural directional attraction of neurites by the sensory epithelium. Neurites spread all over the culture plate (arrows) without preferential orientation as observed in (A) or (B). Staining of Schwann cells [P3 rats; (D), red, arrow heads] demonstrates their contribution to the process of neurite outgrowth toward sensory epithelia. Scale bars $100 \mu \mathrm{m}$. 

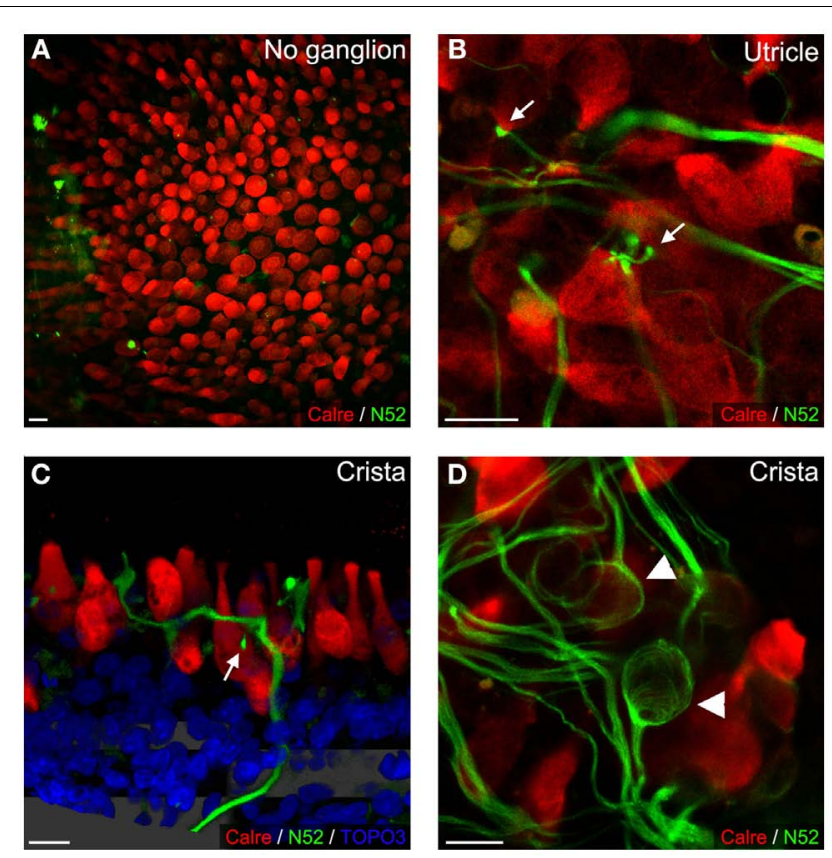

FIGURE 2 | Sensory epithelial innervation in rat co-cultures. After $3 \mathrm{DIV}$, no neurites were observed in P2 utricles cultured alone (A). Conversely, at 6 DIV in the presence of P3 vestibular ganglion, neurites penetrated sensory epithelia and contacted hair cells (B). In utricles and cristae (P5, 10 DIV), bouton-like contacts were observed [(B,C); arrows], while calyceal innervation was only observed in cristae [(D), with arrowheads].

Neurofilament (green), hair cells (red), and occasionally nuclei (blue) were stained. Scale bars $10 \mu \mathrm{m}$.

only bouton-type contacts were observed in utricles (Figure 2B), whereas both bouton and calyx-type contacts were found in the crista ampullaris (Figures 2C,D).

\section{PMA POTENTIATES RE-INNERVATION OF HAIR CELLS BY PRIMARY VESTIBULAR NEURONS}

Phorbol 12-myristate 13-acetate (PMA), an activator of PKC, has been implicated in the regulation of diverse cellular functions (Giorgi et al., 2010), among them, potentiation of dendritic spine development and plasticity (Goldin and Segal, 2003; Ethell and Pasquale, 2005). We tested for potential modulatory effects of PMA on the re-innervation process in vestibular co-cultures of young rodents by examining neurite outgrowth in presence of PMA $(0.1 \mu \mathrm{M}$; rats $n=5)$ in the bathing medium. Confocal imaging was used to track de novo neurite outgrowth from vestibular ganglion neurons up to the contacted hair cells in the sensory epithelia (Figures 3A,B,D). In our model, addition of PMA potentiated the neurite outgrowth process. Gross observation indicated that the presence of PMA increased the number of neural processes growing toward and entering the sensory epithelia (Figures 3A-D). Moreover, under these conditions calyx-type contacts could be observed using $3 \mathrm{D}$ reconstruction in both the utricles (Figure 3C) and cristae (Figure 3E). Table 1 summarizes the results concerning the density, type of innervation, and cell-to-cell contacts in the different culture conditions. Evaluation is ranged as a mean observation obtained from the indicated number of repeated cultures. Although the mechanism underlying PMA potentiation of hair cell re-innervation by primary vestibular neurons remains unknown, it demonstrates the potential for modulating the re-innervation of peripheral vestibular targets.

\section{DE NOVO CELL-TO-CELL CONTACTS DISPLAY CHARACTERISTICS OF SYNAPSES}

To assess whether the de novo cell-to-cell contacts corresponded to synapses between afferent terminals and hair cells, we first used immunohistochemistry to label the pre- and post-synaptic elements. Hair cells were counterstained using calretinin, a calcium binding protein used as a specific marker (Dechesne et al., 1994; Zheng and Gao, 1997). The pre-synaptic ribbons, specific structures controlling the pool of releasable synaptic vesicles, were immuno-localized in the hair cell cytosol using antibodies against ribeye, the main component of the ribbon dense core element (Schmitz et al., 2000; Zanazzi and Matthews, 2009). The postsynaptic terminal element was identified and localized within the sensory epithelia using immunolabeling of synaptophysin. This small synaptic vesicle associated protein is characteristic of vestibular afferent terminals during synaptogenesis (Scarfone et al., 1991; Dechesne et al., 1997; Gaboyard et al., 2003). The juxtaposition of ribeye (Schmitz et al., 2000; Zanazzi and Matthews, 2009) and synaptophysin labeling indicated that the de novo cell-to-cell synaptic contacts were formed correctly at the site of pre-synaptic active zones. At $11 \mathrm{DIV}$ (mice, $n=4$ ), synaptophysin immunolabeling was observed in neuronal processes of both utricles (Figure 4A) and cristae (Figure 4B). In most cases, the synaptophysin immunoreactivity strongly correlated with the ribeye labeling (anti-CtBP2 antibodies; Figure 4B). Note that vesicles spread out along the fibers indicate an immature stage of synaptogenesis.

Subcellular characteristics of the newly formed cell-to-cell contacts were determined using electron microscopy (rats, $n=3$ ). Bouton-type synaptic contacts were observed in crista (Figures 5A,C,D). Afferent terminals full of mitochondria often faced multiple ribbons located in hair cells, surrounded by clusters of mitochondria. Post-synaptic densities (PSD) were observed on membranes of afferent fibers facing pre-synaptic ribbons, confirming that newly formed synaptic contacts were established correctly. Calyx-type terminals were observed entering the sensory cell layer and enveloping type I hair cells (Figures 5B,E-J). Single and multiple ribbons were apposed to the calyx terminal membrane; some facing PSDs were observed on the nerve terminal membrane. Both bouton- and calyx-type terminals were full of mitochondria and vesicles. Two main types of vesicles were identified (Figures 5C,D,E-J): typical small synaptic vesicles and large granular vesicles (almost $100 \mathrm{~nm}$ length) filling both bouton-like terminal endings on type II hair cells and calyx-type climbing terminal afferents along type I hair cells. In summary, in this co-culture model, nerve endings arising from primary vestibular neurons entered vestibular sensory epithelia and contacted both type I and type II hair cells forming calyx- and bouton-type synaptic connections respectively. Several features of these newly formed synaptic contacts (expression of synaptophysin, presence of multiple ribbons, and post-synaptic accumulation of vesicles) suggest that at least up to $18 \mathrm{DIV}$, these contacts remained immature. 

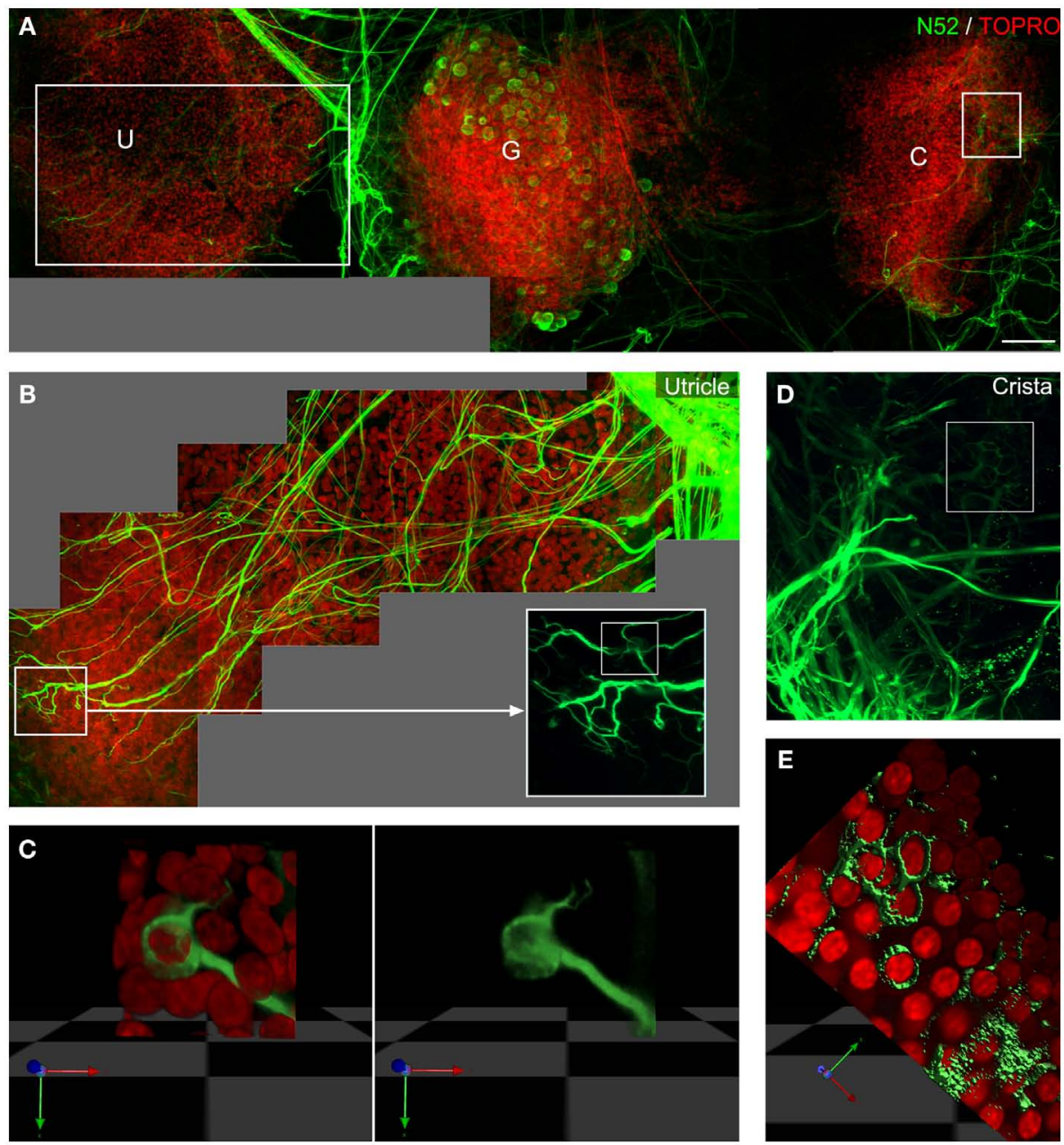

FIGURE 3 | PMA potentiates vestibular synapse formation in vitro. Eighteen DIV co-cultures of P6 rat ganglion (G), utricle (U), and crista (C) in presence of PMA (A-E) illustrates the potentiation of neurite outgrowth and synapse formation in vitro. Insets show higher magnification of utricles (B,C) and cristae (D,E). Multiple neurites were observed inside the utricles and detailed observation [inset, (B)] on nerve endings reconstructed in 3D (C) showed the additional formation of calyceal innervations in utricles. In cristae, PMA increased the number of neurites entering the sensory epithelia (D), and the number of calyces as shown in the $3 D$ reconstruction (E). Neurofilaments stained in green and nuclei in red. Scale bar $100 \mu \mathrm{m}$ (A)

\section{CAPACITY FOR RE-INNERVATION PERSISTS IN MATURE TISSUE}

Since the previously described co-culture experiments were performed using tissue explanted from neonatal rodents with ongoing synaptogenesis, we undertook preliminary experiments to test whether re-innervation capacity remained in mature tissue. Scarpa's ganglia and vestibular epithelia from young adult (Figures 6A,B; 4 weeks old; $n=4$ ) and mature adult (Figures 6C,D; 3 months old; $n=3$ ) rats were co-cultured with PMA added to potentiate the re-innervation and re-connection process. With both young adult and mature adult tissue (Table 1), we observed oriented neurite re-growth toward sensory epithelia, utricles, and crista (Figures 6A,C). At higher magnification, nerve terminals were seen penetrating the sensory cell layer, weaving between hair cells and eventually establishing bouton- and calyx-type contacts (Figures 6B,D). Note that the lack of calretinin labeling at the calyx-type connection supports the hypothesis that this typical synaptic connection was properly formed with mature type I hair cells, as expression of this calcium binding protein is lost after synapse formation. These preliminary experiments suggest that the re-innervation and re-connection capacity was still present in mature tissue following de-afferentation.

\section{DISCUSSION}

\section{SPONTANEOUS SYNAPTIC REPAIR VERSUS DEVELOPMENTAL SYNAPTOGENESIS}

Based on the knowledge of developmental synaptogenesis in mammal vestibular endorgans gathered over the last decades, it can be assumed that the process we report in the present study relies on postlesional repair of damaged vestibular synapses. Indeed, it has been well documented through morphological and functional studies (for review see Eatock and Hurley, 2003) that most afferent fibers arising from Scarpa's ganglion neurons in rodents enter the sensory epithelia a few days before birth, with the first immature synaptic contacts already identifiable at birth. Synapses acquire 
their mature phenotype in the first postnatal days (Desmadryl and Sans, 1990; Dechesne et al., 1994), giving rise to the first recordable synaptic activity (Curthoys, 1982; Desmadryl et al., 1986). During this period, hair cells gradually acquire their mature biophysical properties (Rusch et al., 1998). In the presently described co-cultures prepared from neonatal rodents, the observed ability of primary neurons to restore synaptic contacts with vestibular hair cells may be supported or enhanced by developmental properties that allow formation of native synapses during the first postnatal week. The influence of such developmental

Table 1 | Regeneration of vestibular neurons in different culture conditions. Semi-quantitative comparison of innervation and synaptic contact re-connections evaluated over several experiments (n).

\begin{tabular}{|c|c|c|c|c|c|}
\hline \multirow[t]{2}{*}{ Type of culture } & \multirow[t]{2}{*}{$n$} & \multicolumn{2}{|c|}{ Innervation } & \multicolumn{2}{|c|}{ Synaptic contacts } \\
\hline & & Crista & Utricle & Crista & Utricle \\
\hline Mouse (P2-9) & 12 & ++ & ++ & ++ & + \\
\hline Rat (P2-9) & 10 & ++ & ++ & ++ & + \\
\hline $\begin{array}{l}\text { Mouse or rat (P2-9) } \\
+ \text { BDNF (10 ng/mL) }\end{array}$ & 8 & \pm & \pm & + & + \\
\hline $\begin{array}{l}\text { Rats (P2-9) } \\
+ \text { PMA }(0.1 \mu \mathrm{M})\end{array}$ & 5 & +++ & +++ & +++ & ++ \\
\hline $\begin{array}{l}\text { Rats (>4 weeks) } \\
+ \text { PMA }(0.1 \mu \mathrm{M})\end{array}$ & 7 & ++ & ++ & ++ & ++ \\
\hline
\end{tabular}

Innervation: \pm no preferential direction; ++ orientated; +++ orientated and dense.

Synaptic contacts: + boutons, no calyx; ++ boutons and calyces; +++ numerous boutons and calyces. properties is particularly noticeable in cultures of rodent utricles (Gaboyard et al., 2005), which only retain the remarkable capacity to regenerate a sealed vestibular cyst when removed from their native environment during the first postnatal week (Bartolami et al., 2011). The presently reported process of synaptic repair is in several ways comparable to the regenerative properties in co-cultures of spiral ganglia with denervated organ of Corti from neonate mice (Martinez-Monedero et al., 2006). In this preparation, auditory neurons removed from neonate mice were demonstrated to regenerate processes that grew toward and entered the sensory epithelia, eventually re-innervating hair cells in organs of Corti. Immunocytochemical examinations revealed that the newly formed contacts expressed the synaptic vesicle markers synapsin and SV2 at points of contact with hair cells. The presently observed sustained capacity for neurite regeneration and vestibular organ re-innervation in adult tissue suggests that this repair ability extends beyond the period of neonatal synaptogenesis. It is likely that this property supports the recovery we previously described for adult rats subjected to excitotoxic vestibular insult in vivo (Brugeaud et al., 2007). Further experiments will be required to examine whether the re-innervation process results in functional synapses and whether the mechanism underlying the regenerative process is identical during the neonate and adult periods.

\section{DIVERSE FACTORS ARE POTENTIAL MODULATORS OF SYNAPTIC REPAIR}

Although a direct quantification of reconstituted synaptic contacts was not undertaken in the present study, our qualitative and descriptive approach unambiguously demonstrates that neuronal processes grew from Scarpa's ganglion primary vestibular neurons placed in close proximity to the sensory epithelia, entered
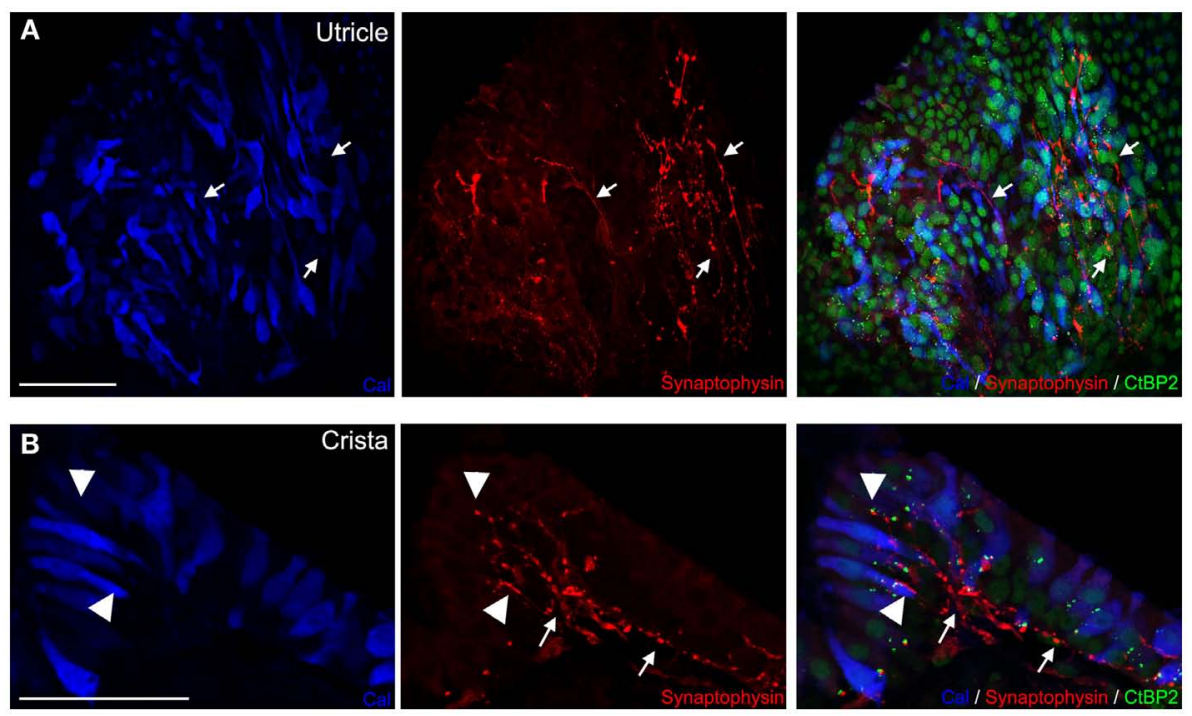

FIGURE 4 | Maturing synaptic contacts. In utricles (A) and cristae (B) of 11 DIV co-cultures of P4 rats, synaptic contacts were stained and observed between hair cells (blue) and neurites. Anti-CtBP2 antibodies used to label the ribeye protein, major molecular component of synaptic ribbons (green, small bright dots) and nuclei of hair cells, while anti-synaptophysin antibodies labeled small synaptic vesicles (red) contained in maturing synaptic afferents. Terminals of innervating fibers (arrows) entering sensory epithelia were observed. Co-labeling with ribeye shows close apposition of these synaptic terminals with ribbons in hair cells (arrow heads) in both cristae (A) and utricles (B). Scale bars $50 \mu \mathrm{m}$. 

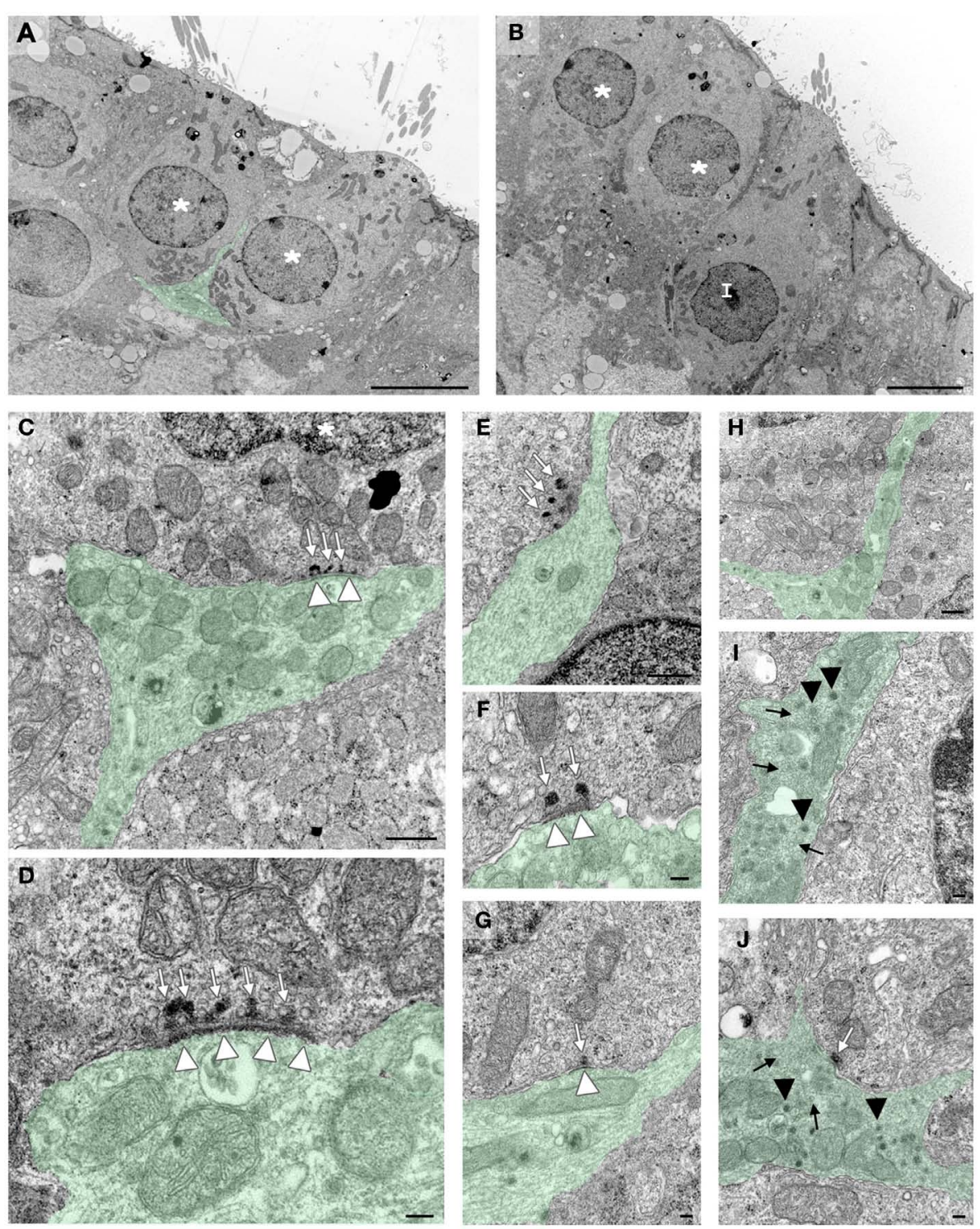

FIGURE 5 | Details of synaptic contacts. In crista, electron microscopy highlights the different synaptic contacts formed de novo between hair cells and vestibular afferent terminals in 18 DIV co-cultures from P6 rats. Some fibers (green) contact multiple hair cells [(A), stars], while others contact only one hair cell forming a terminal that ensheathes the pre-synaptic type I hair cell [(B), I]. Bouton terminals (C,D) contact hair cells. Ribbons (white arrows) in hair cells face synaptic densities (white arrow heads). The fibers ensheating the type I-like hair cells (E-J) display typical features of mature and immature calyceal terminals. Fibers climb along the hair cell membrane facing ribbons (E-G), presenting some post-synaptic densities $(\mathbf{F}, \mathbf{G})$. Contacts with multiple $\mathbf{( E , F )}$ or single $(\mathbf{G})$ ribbons were found. In these growing afferent fibers $(\mathbf{H}-\mathbf{J})$ typical small synaptic vesicles of immature calyceal innervations were observed in the newly formed terminals (black arrows) $\mathbf{( I , J ) . ~ L a r g e ~ g r a n u l a r ~}$ vesicles (black arrow head) typical of peptidergic synaptic vesicles were also present in these growing calyceal terminals $(\mathbf{I}, \mathbf{J})$. Scale bars $5 \mu \mathrm{m}$ in $(\mathbf{A}, \mathbf{B})$,

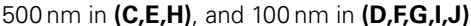

the epithelia, and re-innervated hair cells at pre-synaptic active zones. This is substantiated by electron microscopy analysis and demonstration of the juxtaposition of synaptophysin immunolabeling, characteristic of connected neuronal processes (Scarfone et al., 1991; Dechesne et al., 1997; Gaboyard et al., 2003) and CtBP2 immunoreactivity characteristic of ribeye protein present at presynaptic active zones in hair cells (Schmitz et al., 2000; Zanazzi and Matthews, 2009). It is possible that the reported regenerative and plastic capacities observed for part of the neuronal population in the co-culture model in vitro may be more robust in native tissue.
Indeed, in vivo, several endogenous factors have been demonstrated to play a critical role in the guidance of fibers toward their targets and in the synaptogenesis process. Using BDNF deficient mice, it was previously demonstrated that BDNF controls the guidance of nerve fibers arising from Scarpa's ganglion neurons toward the sensory epithelia (Ernfors et al., 1995). In the present study, BDNF application in the culture medium altered the preferred orientation of neurite outgrowth toward sensory epithelia. This confirms that (at least during the developmental process of synaptogenesis) controlled release of BDNF by the targeted cells 

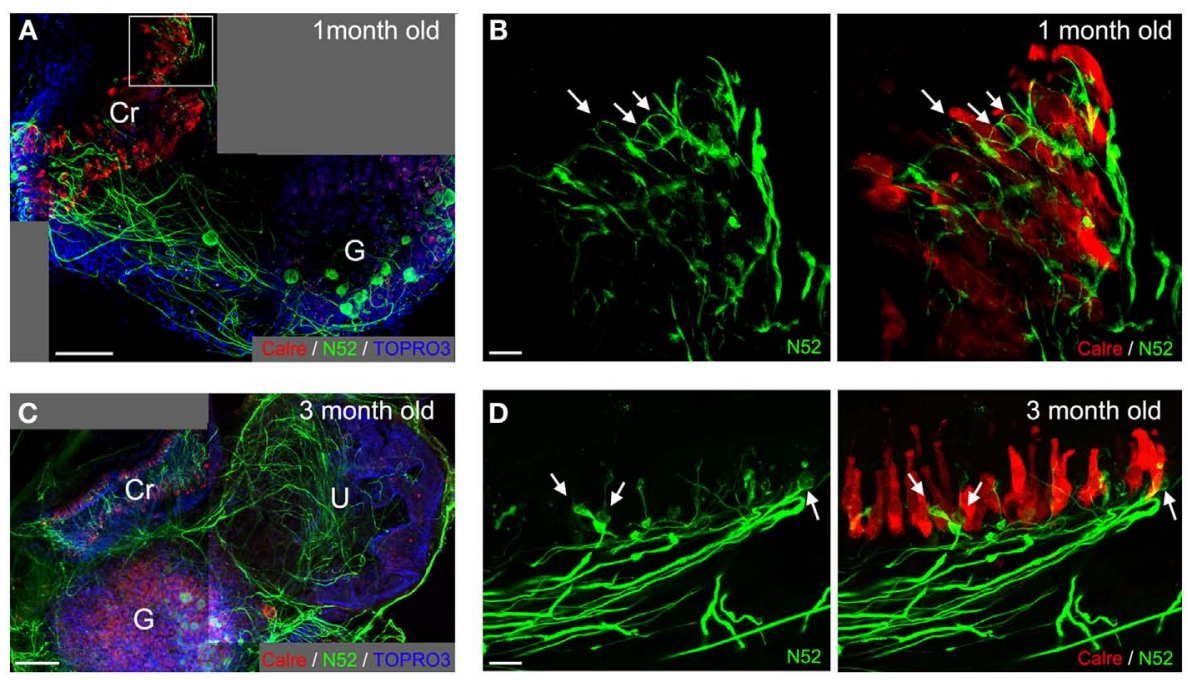

FIGURE 6 | Repair capacity is conserved in mature tissue. In 17 DIV co-cultures from 4 week old $(\mathbf{A}, \mathbf{B})$ and 19 DIV co-cultures from 3 months old (C,D) animals, re-innervation of vestibular epithelia by primary afferents was still observed. At low magnification $(\mathbf{A}, \mathbf{C})$, we observed nerve fibers (green) preferentially growing toward the sensory epithelia. At higher magnification (B,D), contacts between hair cells (red) and neurites were observed. Even calyceal terminals were observed (arrows) at both ages in the presence of PMA. Nuclei were stained with ToPro3, blue in $(\mathbf{A}, \mathbf{C})$. Scale bars $100 \mu \mathrm{m}$ in $(\mathbf{A}, \mathbf{C})$ and, $10 \mu \mathrm{m}$ in $\mathbf{( B , D )}$. or their immediate environment is required for directional control of neurite outgrowth (Brugeaud et al., 2007). In this study, we also reported the involvement of Schwann cells in supporting and/or accompanying the re-innervation process, and we observed the potentiating effect of PMA on neurite outgrowth. Numerous other factors in vivo may play essential roles in this process. In particular, the role of efferent terminals in providing feedback input from the brain stem may participate in the maturation of synapses between hair cells and primary vestibular neurons (Favre and Sans, 1977; Desmadryl et al., 1992; Dememes et al., 2001). In the present co-culture model, the lack of efferent fibers may contribute to the immaturity of the newly formed synaptic contacts, characterized by the presence of multi ribbons in hair cells, as well as the increased expression of synaptophysin and accumulation of vesicles in afferent terminals. However, immature expression of synaptophysin may also suggest that the reparative de novo synaptogenesis recapitulates stages of developmental synaptogenesis. In support of this latter hypothesis, we previously demonstrated that hair cells of adult rat utricles in vivo control the re-formation of synaptic contacts with afferents after excitotoxic damage by re-expression of a voltage-gated sodium conductance (Brugeaud et al., 2007) otherwise restricted to the developmental synaptogenesis stage (Chabbert et al., 2003). Whether primary vestibular neurons re-innervating hair cells re-establish pre-lesional branching patterns is an important question that needs to be addressed to substantiate the functional consequences of the re-innervation process. In the adult pigeon, elegant experiments have demonstrated that calyceal, dimorphic, and bouton afferents all regenerated with normal epithelial topographical distribution following complete vestibular sensory receptor loss and epithelial denervation, albeit following a slower time course. However, it was noted that regenerated afferent terminals were significantly smaller, had reduced morphological complexity and innervated fewer sensory cells in reduced epithelial areas than those developed through normal morphogenesis (Haque et al., 2009).

\section{CONCLUSION}

Whether newly formed neurite to hair cell contacts lead to functional synapses can only be answered by monitoring recovery of synaptic activity in co-cultures following complete denervation of the sensory epithelia. An adequate paradigm to record such activity is currently under development in our lab. Nevertheless, the observations presented in this study further emphasize the remarkable capacity of primary vestibular neurons to restore synaptic contacts with available targets, assuming sufficient proximity and/or appropriate guidance. Identification of the molecular and cellular mechanisms underlying such plastic capacities is a prerequisite for the development of therapeutic strategies to protect and repair vestibular sensory synapses. Such approaches could directly facilitate the treatment lasting functional impairments of peripheral origin encountered following, e.g., vestibular neuritis or vertebrobasilar stroke. Moreover, such knowledge could open new therapeutic opportunities to the pharmacological control of neuronal regeneration and synaptic repair at a time where significant progress exists in vestibular prosthesis (Della Santina et al., 2011; van de Berg et al., 2011).

\section{ACKNOWLEDGMENTS}

We thank Pr. Alain Sans for his pioneer studies and his transmitted interest in the vestibule morphophysiology. We are grateful to Dr. Jonas Dyhrfjeld-Johnsen for scientific discussion and critical reading of the manuscript. We thank the RHEM INM (Montpellier, France) for technical assistance for tissue preparation, the MRI INM (Montpellier, France) for assistance with imaging, and for CRIC (Montpellier, France) for assistance with electron microscopy. 


\section{REFERENCES}

Bartolami, S., Auge, C., Travo, C., Venteo, S., Knipper, M., and Sans, A. (2003). Vestibular Schwann cells are a distinct subpopulation of peripheral glia with specific sensitivity to growth factors and extracellular matrix components. J. Neurobiol. 57, 270-290.

Bartolami, S., Gaboyard, S., Quentin, J., Travo, C., Cavalier, M., Barhanin, J., and Chabbert, C. (2011). Critical roles of transitional cells and $\mathrm{Na} / \mathrm{K}$-ATPase in the formation of vestibular endolymph. J. Neurosci. 31, 16541-16549.

Brugeaud, A., Travo, C., Dememes, D., Lenoir, M., Llorens, J., Puel, J. L., and Chabbert, C. (2007). Control of hair cell excitability by vestibular primary sensory neurons. J. Neurosci. 27, 3503-3511.

Chabbert, C., Mechaly, I., Sieso, V., Giraud, P., Brugeaud, A., Lehouelleur, J., Couraud, F., Valmier, J., and Sans, A. (2003). Voltage-gated $\mathrm{Na}+$ channel activation induces both action potentials in utricular hair cells and brain-derived neurotrophic factor release in the rat utricle during a restricted period of development. J. Physiol. (Lond.) 553, 113-123.

Choi, K. D., Oh, S. Y., Kim, H. J., Koo, J. W., Cho, B. M., and Kim, J. S. (2007). Recovery of vestibular imbalances after vestibular neuritis. Laryngoscope 117, 1307-1312.

Curthoys, I. S. (1982). Postnatal developmental changes in the response of rat primary horizontal semicircular canal neurons to sinusoidal angular accelerations. Exp. Brain Res. 47, 295-300.

Dechesne, C. J., Kauff, C., Stettler, O., and Tavitian, B. (1997). Rab3A immunolocalization in the mammalian vestibular end-organs during development and comparison with synaptophysin expression. Brain Res. Dev. Brain Res. 99, 103-111.

Dechesne, C. J., Rabejac, D., and Desmadryl, G. (1994). Development of calretinin immunoreactivity in the mouse inner ear. J. Comp. Neurol. 346, 517-529.

Della Santina, C. C., Migliaccio, A. A., Hayden, R., Melvin, T. A., Fridman, G. Y., Chiang, B., Davidovics, N. S., Dai, C., Carey, J. P., Minor, L. B., Anderson, I. C., Park, H., Lyford-Pike, S., and Tang, S. (2011). Current and future management of bilateral loss of vestibular sensation - an update on the Johns Hopkins multichannel vestibular prosthesis project. Cochlear Implants Int. 11(Suppl. 2), 2-11.

Dememes, D., Dechesne, C. J., Venteo, S., Gaven, F., and Raymond, J. (2001). Development of the rat efferent vestibular system on the ground and in microgravity. Brain Res. Dev. Brain Res. 128, 35-44.

Desmadryl, G., Dechesne, C. J., and Raymond, J. (1992). "Recent aspect of development of the vestibular sense organs and their innervation," in Development of Auditory and Vestibular Systems, ed. R. Romand (Amsterdam: Elsevier Scientific), 461-487.

Desmadryl, G., Raymond, J., and Sans, A. (1986). In vitro electrophysiological study of spontaneous activity in neonatal mouse vestibular ganglion neurons during development. Brain Res. 390, 133-136.

Desmadryl, G., and Sans, A. (1990). Afferent innervation patterns in crista ampullaris of the mouse during ontogenesis. Brain Res. Dev. Brain Res. 52, 183-189.

Eatock, R. A., and Hurley, K. M. (2003). Functional development of hair cells. Curr. Top. Dev. Biol. 57, 389-448.

Ernfors, P., Van De Water, T., Loring, J., and Jaenisch, R. (1995). Complementary roles of BDNF and NT-3 in vestibular and auditory development. Neuron 14, 1153-1164.

Ethell, I. M., and Pasquale, E. B. (2005). Molecular mechanisms of dendritic spine development and remodeling. Prog. Neurobiol. 75, 161-205.

Favre, D., and Sans, A. (1977). Synaptogenesis of the efferent vestibular nerve endings of the cat: ultrastructural study. Arch. Otorhinolaryngol. 215, 183-186.

Freyss, G., De Saint-Macary, M., and Henin, J. M. (1973). Graphic presentation of the vestibular caloric test. Ann. Otolaryngol. Chir. Cervicofac. 90, 745-761.

Gaboyard, S., Chabbert, C., Travo, C., Bancel, F., Lehouelleur, J., Yamauchi, D., Marcus, D. C., and Sans, A. (2005). Three-dimensional culture of newborn rat utricle using an extracellular matrix promotes formation of a cyst. Neuroscience 133, 253-265.

Gaboyard, S., Sans, A., and Lehouelleur, J. (2003). Differential impact of hypergravity on maturating innervation in vestibular epithelia during rat development. Brain Res. Dev. Brain Res. 143, 15-23.

Giorgi, C., Agnoletto, C., Baldini, C. Bononi, A., Bonora, M., Marchi, S., Missiroli, S., Patergnani, S., Poletti, F., Rimessi, A., Zavan, B., and Pinton, P. (2010). Redox control of protein kinase C: cell- and disease-specific aspects. Antioxid. Redox Signal. 13, 1051-1085.

Goldin, M., and Segal, M. (2003). Protein kinase $\mathrm{C}$ and ERK involvement in dendritic spine plasticity in cultured rodent hippocampal neurons. Eur. J. Neurosci. 17, 2529-2539.

Haid, T., and Mirsberger, J. (1985). Peripheral vestibular neuropathy and a central vestibular equivalent. HNO 33 , 262-270.

Haque, A., Zakir, M., and Dickman, J. D. (2009). Regeneration of vestibular horizontal semicircular canal afferents in pigeons. J. Neurophysiol. 102, 1274-1286.

Hernandez, J. D., Hoffman, L. F. and Honrubia, V. (1998). Vestibular nerve regeneration in the bullfrog, Rana catesbeiana: peripheral dendrites. Otolaryngol. Head Neck Surg. 119, 244-254.

Kujawa, S. G., and Liberman, M. C. (2009). Adding insult to injury: cochlear nerve degeneration after "temporary" noise-induced hearing loss. J. Neurosci. 29, 14077-14085.

Lin, H. W., Furman, A. C., Kujawa, S. G., and Liberman, M. C. (2011). Primary neural degeneration in the Guinea pig cochlea after reversible noise-induced threshold shift. J. Assoc. Res. Otolaryngol. 12, 605-616.

Liu, T. C. (1999). The effects of kainic acid on the vestibular ganglion cells. Neurosci. Res. Commun. 24, 8.

Martinez-Monedero, R., Corrales, C. E., Cuajungco, M. P., Heller, S. and Edge, A. S. (2006). Reinnervation of hair cells by auditory neurons after selective removal of spiral ganglion neurons. J. Neurobiol. 66, 319-331.

Olney, J. W. (1969). Brain lesions, obesity, and other disturbances in mice treated with monosodium glutamate. Science 164 719-721.

Pujol, R., and Puel, J. L. (1999). Excitotoxicity, synaptic repair, and functional recovery in the mammalian cochlea: a review of recent findings. Ann. N. Y. Acad. Sci. 884, 249-254.
Ruel, J., Wang, J., Rebillard, G., Eybalin, M., Lloyd, R., Pujol, R., and Puel, J. L. (2007). Physiology, pharmacology and plasticity at the inner hair cell synaptic complex. Hear. Res. 227, 19-27.

Rusch, A., Lysakowski, A., and Eatock, R. A. (1998). Postnatal development of type I and type II hair cells in the mouse utricle: acquisition of voltage-gated conductances and differentiated morphology. J. Neurosci. 18, 7487-7501.

Scarfone, E., Dememes, D., and Sans, A. (1991). Synapsin I and synaptophysin expression during ontogenesis of the mouse peripheral vestibular system. J. Neurosci. 11, 1173-1181.

Schmitz, F., Konigstorfer, A., and Sudhof, T. C. (2000). RIBEYE, a component of synaptic ribbons: a protein's journey through evolution provides insight into synaptic ribbon function. Neuron 28, 857-872.

Seoane, A., Dememes, D., and Llorens, J. (2001). Pathology of the rat vestibular sensory epithelia during subchronic 3,3'iminodipropionitrile exposure: hair cells may not be the primary target of toxicity. Acta Neuropathol. 102, 339-348.

Shimogori, H., and Yamashita, H. (2004). Peripheral vestibular disorder induced by ( \pm )-alpha-amino-3-hydroxy-5methyl-isoxazole-4-propionic acid (AMPA). Neurosci. Lett. 371, 69-72.

van de Berg, R., Guinand, N., Stokroos, R. J., Guyot, J. P., and Kingma, H. (2011). The vestibular implant: quo vadis? Front. Neurol. 2:47. doi:10.3389/fneur.2011. 00047

Vignaux, G., Chabbert, C., GaboyardNiay, S., Travo, C., Machado, M. L., Denise, P., Comoz, F., Hitier, M., Landemore, G., Philoxéne, B., and Besnard, S. (2012). Evaluation of the chemical model of vestibular lesions induced by arsanilate in rats. Toxicol. Appl. Pharmacol. 258, 61-71.

Zakir, M., and Dickman, J. D. (2006). Regeneration of vestibular otolith afferents after ototoxic damage. J. Neurosci. 26, 2881-2893.

Zanazzi, G., and Matthews, G. (2009). The molecular architecture of ribbon presynaptic terminals. Mol. Neurobiol. 39, 130-148.

Zhang, M., and Yannas, I. V. (2005). Peripheral nerve regeneration. Adv. Biochem. Eng. Biotechnol. 94, 67-89. 
Zheng, J. L., and Gao, W. Q. (1997). Analysis of rat vestibular hair cell development and regeneration using calretinin as an early marker. J. Neurosci. $17,8270-8282$.

Conflict of Interest Statement: The authors declare that the research was conducted in the absence of any commercial or financial relationships that could be construed as a potential conflict of interest.

Received: 02 December 2011; paper pending published: 12 January 2012; accepted: 19 May 2012; published online: 06 June 2012.
Citation: Travo C, Gaboyard-Niay S and Chabbert C (2012) Plasticity of Scarpa's ganglion neurons as a possible basis for functional restoration within vestibular endorgans. Front. Neur. 3:91. doi: 10.3389/fneur.2012.00091

This article was submitted to Frontiers in Neuro-otology, a specialty of Frontiers in Neurology.
Copyright (c) 2012 Travo, GaboyardNiay and Chabbert. This is an openaccess article distributed under the terms of the Creative Commons Attribution Non Commercial License, which permits non-commercial use, distribution, and reproduction in other forums, provided the original authors and source are credited. 